\title{
Spatial Identification and Development Sequence of Coal Mine Tourism Resources
}

\author{
Qiu-Ju Wang, ${ }^{1}$ Zhi-Hong Wang, ${ }^{2}$ Jia-Li Zhou, ${ }^{1}$ and Shuang Dong ${ }^{1 *}$ \\ ${ }^{1}$ Beijing Union University, No. 99 Beisihuandong Road, Chaoyang District, Beijing 100101, China \\ ${ }^{2}$ Shenyang University, No. 21 Wanghuanan Street, Dadong District, Shenyang 110044, China
}

(Received May 12, 2020; accepted August 25, 2020)

Keywords: industrial heritage, tourism resources, spatial pattern, nuclear density analysis, grid overlay analysis

This article comprehensively categorizes the importance of coal mines that operated during the history of modern coal mining from 1840 to 1970 and evaluates the value of the tourism resources of each coal mine. By combining the values of coal mine tourism resources and the point data on coal-resource-exhausted cities, the nuclear density analysis method is used to form corresponding nuclear density distribution maps; nuclear density reclassification and assignment and overlay analysis are used to identify the key cities and regions suitable for the development of coal mine industrial heritage tourism. On this basis, the development sequence and measures for the development of coal mine industrial heritage tourism are proposed. The study found that the integration of multiple spatial technology analysis methods can effectively solve the problems of spatial identification of coal mine tourism resources. Coal mine tourism resources are mainly concentrated in five regions: the northeast region, northern Huang-Huai, the northeast of central China and northwest China, the east of northwest China, and central Jiangnan. In the future, industrial heritage tourism should be developed according to the law of gradient development. Priority should be given to the development of areas with exhausted resources and a high value of tourism resources to gradually form four clusters of coal mine industrial heritage tourism corresponding to tourism resources.

\section{Introduction}

In recent years, with the continuous slowdown of economic growth, the shrinking demand for coal and excess capacity in China have put unprecedented pressure on coal mines and their locations. It is an urgent and necessary task for mines to seek alternative channels for economic growth and realize regional economic transformation.

Industrial heritage tourism is one of the important channels for the economic transformation of resource-based cities. Traditional old industrial areas such as the northern part of Manchester, the Ruhr area of Germany, and the Lorraine area of France have achieved sustainable regional economic development through the development of industrial heritage tourism. Many coal-based cities in China are prosperous owing to mining. In the historical

*Corresponding author: e-mail: gltdongshuang@buu.edu.cn

https://doi.org/10.18494/SAM.2020.2942 
development of the cities, coal mining heritage with rich connotations, diverse forms, and unique characteristics has been formed. Since 2004, China has actively explored the development of industrial heritage tourism in abandoned coal mines. A total of 88 national mine parks have been approved. Policy documents such as the National Industrial Tourism Development Outline (2016-2025) and (Draft for Comment), the 13th Five-Year Tourism Development Plan, and Opinions on Exploring the Use of Market-Oriented Methods to Promote Ecological Restoration of Mines have been issued to support the development of industrial heritage in resource-based cities. Cities based on coal resources have been provided with an opportunity to develop tourism based on industrial heritage. Not all coal mines are suitable for the development of industrial heritage tourism. The endowment of tourism resources is the premise and foundation of industrial heritage tourism development. In this new situation, it is of great significance to identify the spatial distribution of coal mine tourism resources.

Foreign academic circles began to pay attention to industrial heritage tourism resources in the 1950s. The American scholar D. B. Steinman first proposed the practical significance of industrial heritage protection from the perspective of industrial archeology. Then, with the increase in the number of abandoned mines in western countries, many scholars have conducted related research studies on mining heritage resources from the perspectives of tourism, cultural heritage protection, planning, and energy economy. Following this, industrial heritage tourism resources, ${ }^{(1-3)}$ the evaluation of the value of industrial heritage tourism resources, ${ }^{(4-6)}$ the development models of industrial heritage tourism resources, ${ }^{(7-10)}$ the impact of developing industrial heritage tourism resources on the regional economy, ${ }^{(11,12)}$ the behavior of tourists at industrial heritage sites, and other aspects have become hot topics in China and worldwide.

In recent years, Chinese scholars have conducted a series of studies exploring the spatial distribution of industrial heritage tourism development. Some scholars have studied the spatial evolution characteristics of mining relics and industrial tourism demonstration sites, ${ }^{(13)}$ models, ${ }^{(14)}$ and the characteristics of industrial development in various regions. ${ }^{(15)}$ Some scholars have studied the spatiotemporal distribution characteristics of China's national mine parks and their influencing factors. ${ }^{(16-18)}$ These studies have laid important foundations for this article, but there are still many problems, as follows: (1) Research has focused on the identification of tourism resources in a certain mine or resource-based city rather than the overall identification of tourism resources in China formed as a result of its coal mining history. (2) Regarding the aspect of spatial identification, only the spatial distribution of completed industrial tourism destinations has been studied. There has been little research on the spatial expression of tourism resources, so the basis of scientific decision-making for the development of tourism resources in coal mines has not been provided.

This article comprehensively categorizes the importance of coal mines that operated during China's modern coal mining history from 1840 to 1970 and evaluates the value of the tourism resources of each coal mine. By combining the values of coal mine tourism resources and the point data on coal-resource-exhausted cities, the nuclear density analysis method is used to form corresponding nuclear density distribution maps; nuclear density reclassification and assignment and overlay analysis are used to identify the key cities and regions suitable for the development of coal mine industrial heritage tourism. On this basis, the development sequence and measures for the development of coal mine industrial heritage tourism are proposed. 


\section{Data Sources and Methods}

\subsection{Data sources}

We comprehensively combed the development history of modern coal mining from 1840 to 1970 and adopted the literature induction method to screen import coal mines operating in China in different periods. Our main source of coal-resource-exhausted cities was the lists of national resource-exhausted cities identified by the National Development and Reform Commission in 2008, 2009, and 2012. Google Earth was used to obtain the geographic coordinate data of key coal mines and coal-resource-exhausted cities, and taking the national vector map of 1:4 million as the base map, ArcGIS10.1 software was used to match the geographic space of key coal mines and coal-resource-exhausted cities, and the corresponding spatial database was established.

\subsection{Research methods}

(1) Nuclear density analysis

Geographic information system (GIS) spatial density analysis is based on the use of input point functions to analyze the spatial density of data to calculate the aggregate state of an entire region and thus create a coherent density layer. In the calculation process, a query is made in a circular area centered on each grid point to be calculated, and the points close to the center of the grid search area are given a higher specific gravity. As the distance from the center of the grid increases, the specific gravity decreases. The nuclear density analysis method is generally carried out as follows: $f(x)$ at a point $x$ is usually estimated using the Rosenblatt-Parzen kernel:

$$
f_{n}(x)=\frac{1}{n h^{d}} \sum_{i=1}^{n} k\left[\frac{x-x_{i}}{h}\right]
$$

The kernel density estimation method is used to explore the spatial distribution characteristics and changes of elements in the region, so as to reflect the dispersion or aggregation distribution state of spatial elements. The "density analysis" function module in the Spatial Analyst tool of ArcGIS10.1 software is used for kernel density analysis.

(2) Overlay analysis

This is a very important spatial analysis function in a GIS. It refers to the process of generating new data through a series of set operations on two data under a unified spatial reference system. The data mentioned here can be a data set corresponding to a layer or a ground object. The aim of superposition analysis is to analyze the relationship between spatial characteristics and exclusive attributes of spatial objects whose spatial positions are related to each other. Through the superposition analysis of the values of coal mine tourism resources and the point data of coal-resource-exhausted cities, we produce a new attribute characteristic relation, thus finding the connection between the two layers of data, and identify the key areas for the development of coal mine industrial heritage tourism. 


\section{Spatial Identification of Coal Mine Tourism Resources}

\subsection{Key coal mines during the coal mining history of China}

China's coal mining originated from the middle and lower reaches of the Yangtze River and the Beijing-Tianjin-Tangshan region. Relying on rich coal resources and superior transportation conditions, these regions include Zhili Cizhou Coal Mine, Hubei Coal and Iron Administration, Taiwan Keelung Coal Mine, Anhui Chizhou Coal Mine, Li Kaiping Coal Mine, Hubei Jingmen Coal Mine, Shandong Yixian Coal Mine, Guangxi Fuchuan Coal Mine, Zhili Lincheng Coal Mine, Jiangsu Xuzhou Coal Mine, Fengtian Jinzhou Luomashan Coal Mine, Anhui Guichi Coal Mine, Beijing Xishan Coal Mine, Shandong Zichuan Coal Mine, Hubei Daye Coal Mine, Hubei Maanshan Coal Mine, and other coal mines, which have become the most prosperous coal mines in China's modern coal industry. ${ }^{(19)}$

After the Sino-Japanese war of 1894-1895, Japan seized the coal mining rights in Fushun, Benxi Lake, Yantai, Xuancheng, Anhui, and other places in northeast China, and the coal industry in northeast China and central China was developed. Later, Britain, Germany, France, and the United States also contributed to the development of Chinese coal mines. At the same time, patriots in China also founded a large number of coal mines. Driven by foreign capital and national capital, there were more than 130 coal mines by the time the People's Republic of China was founded in 1949. China's coal mining initially formed four major agglomeration areas: northeast China, Jinluyu district, Chuanqianyu district, and Xiangegan district. After the founding of the People's Republic of China, China vigorously developed the coal industry and established many new coal mines.

During the first Five-Year Plan period (1953-1957), 15 old mining areas, Tangshan, Datong, Fuxin, Hegang, Yangquan, Huainan, Fengfeng, Pingxiang, Jiaozuo, Zaozhuang, Xinwen, Jixi, Tonghua, Liaoyuan, and Xuzhou, were mainly expanded. At the same time, the construction of new coal mines, such as Pingdingshan, Baotou, Lu'an, Hebi, Zhongliangshan, Xinglong, Xuangang, Fenxi, Shandan, and Shizuishan, began.

During the second Five-Year Plan period (1958-1962), 40 new mining areas were constructed, including Handan, Jincheng, Wuda, Huaibei, Fengcheng, Lianshao, Tiefa, Qitaihe, Guangwang, Liuzhi, Pingshi, and Nanning.

During the third Five-Year Plan period (1966-1970), the construction of the "big third line" of the coal industry was carried out, including more than 10 mining areas in the southwest and northwest, namely, Liuzhi, Panxian, and Shuicheng in the Guizhou mining area; Dukou, Hibiscus, Songzao, and Huayingshan in the Sichuan mining area; Shizuishan and Shitanjing in the Ningxia mining area; Tongchuan, Pubai, Chenghe, and Hancheng in the Shanxi mining area; Qingyuan and Yaojie in the Gansu mining area; Datong in the Qingha mining area; Hami in the Xinjiang mining area; and Wuda in the Inner Mongolia mining area. New coal mining cities such as Qitaihe in Heilongjiang were also established beyond the big third line.

During the fourth Five-Year Plan period (1971-1975), 13 new mining areas including Panji, Fengfeng, Yongan, Hancheng, Chenghe, Huaying Mountain, Tianba, and Housuo had been built. ${ }^{(20)}$ 


\subsection{Spatial distribution characteristics of tourism resources}

Coal mine tourism resources are production facilities, such as tunnels, open pit mines, ore-processing facilities, slag wastes, transportation roads, machines, and tools, which are attractive to tourists, as well as administrative facilities, living space, service space, and intangible cultural heritage that serve mine production. The development of coal mine industrial heritage tourism mainly relies on the most valuable part of tourism resources, which is industrial heritage. The higher the value of industrial heritage, the higher the value of tourism development. At present, China does not collect special statistics on the value of the industrial heritage of coal mines. In this paper, the duration of coal mining is taken as an alternative index to measure the value of tourism resources. The longer the history of coal mine construction, the greater its value. This is the standard for the evaluation of the value of tourism resources. The specific evaluation criteria for the value of tourism resources are as follows: coal mines operating from the emergence of the modern coal industry in China to the founding of the People's Republic of China (1840-1949) are valued at 1 point; coal mines operating from the initial development period of China's socialist coal industry (1949-1958) are valued at 0.8 points; coal mines developed during the second and third five-year periods of socialist development (1958-1970) are valued at 0.6 points; and important coal mines and ordinary mines established after 1970 are respectively valued at 0.4 and 0.2 points. At the same time, the degree of industrial heritage preservation is taken as the translation coefficient of the heritage value. After the evaluation, the value of the industrial heritage needs to be multiplied by the translation coefficient to calculate the final value.

The "density analysis" function module in the Spatial Analyst tool of ArcGIS10.1 software was used to conduct kernel density analysis on the value of coal mine tourism resources. To maximize the effectiveness, the search radius was set as $500 \mathrm{~km}$ several times during the analysis. The spatial distribution of the values of coal mine tourism resources is shown in Fig. 1.

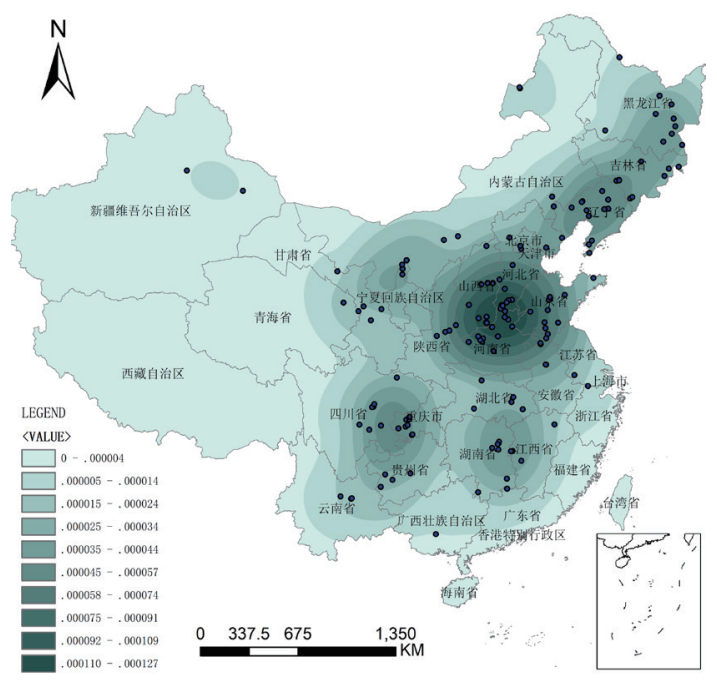

Fig. 1. (Color online) Spatial distribution of values of coal mine tourism resources. 
The value of coal mine tourism resources presents the characteristics of a multicenter agglomeration. The dense centers are mainly distributed in the northeast region, northern Huang-Huai, the northeast of central China and northwest China, the east of northwest China, and central Jiangnan. The largest regional central poles appear in Beijing, Hebei, Henan, Tianjin, Shandong, and Shanxi. The value of tourism resources tends to decrease from central and eastern to inland cities in the central and western regions.

\section{Identification of Key Areas for Development of Coal Mine Industrial Heritage Tourism}

\subsection{Spatial distribution characteristics of coal-resource-exhausted cities}

Some of the coal mines with high values of tourism resources are still in operation, while others have exhausted their resources and have been closed down. The economic transformation of coal mines with exhausted resources is urgent, which is the focus of the development of coal mine tourism resources. For this reason, we first analyze the spatial distribution of coal-resource-exhausted cities, then identify the key areas suitable for the development of coal mine tourism resources and put forward a time sequence for the development of China's coal mine industrial heritage tourism.

In 2008, 2009, and 2012, the National Development and Reform Commission identified a total of 69 national resource-exhausted cities, 34 of which were coal-exhausted cities, accounting for $49.3 \%$ of the total, and most of them are distributed in northeast China and traditional coal-mining areas. In this paper, the "density analysis" functional module of the ArcGIS10.1 software Spatial Analyst tool was used to analyze the core density of coal-resource-exhausted cities. To ensure the best results, the search radius was set as $400 \mathrm{~km}$ many times during the analysis. The obtained spatial distribution of coal-resource-exhausted cities is shown in Fig. 2.

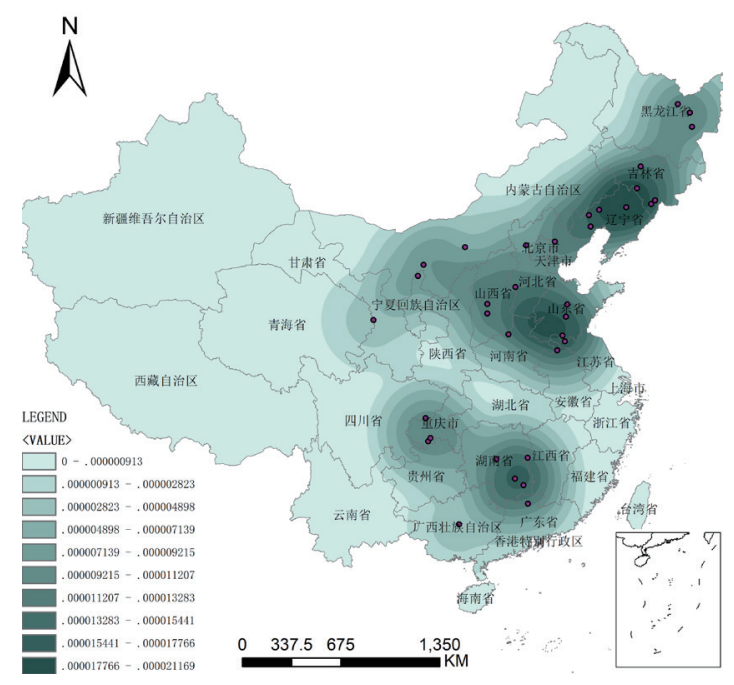

Fig. 2. (Color online) Spatial distribution of coal-resource-exhausted cities. 
The spatial distribution of coal-resource-exhausted cities in China is also characterized by a multicenter agglomeration. The dense spatial distribution centers of coal-resource-exhausted cities are mainly in the eastern part of Heilongjiang, the central and southern parts of Liaoning, the Shandong peninsula, the central plains, the Chengdu-Chongqing region, and the middle reaches of the Yangtze River in Shanxi.

\subsection{Identification of key areas for development of coal mine industrial heritage tourism}

By combining the distribution map of the values of tourism resources and the distribution map of the values of coal-resource-exhausted cities, the spatial distribution of coal mines with high values of tourism resources and exhausted resources is identified by reclassification, valuation, and superposition analysis. Firstly, the nuclear density analysis results of the value of tourism resources in coal mines and the coal-resource-exhausted cities are reclassified into five categories by the natural breakpoint method, which are valued 1,2,3,4, and 5. The reclassified results of the nuclear density analysis of coal-resource-exhausted cities are shown in Fig. 3.

Using the reclassification results, superposition analysis is carried out by adding the nuclear density grade of the values of coal mine tourism resources and coal-resource-exhausted cities, and the distribution of areas suitable for the development of coal mine industrial heritage tourism is obtained. Areas with superposition values from 2 to 10 are shown in different colors in Fig. 4. To clarify the development time sequence, the superposition score is divided into three development gradients: $9-10$ is the first development gradient, $7-8$ is the second development gradient, and 5-6 is the third development gradient. Values of less than 5 are the targets of long-term development. The first and second development gradients mainly correspond to regions with high values of coal mine tourism resources whose coal resources are on the verge of exhaustion, which are mainly distributed in the northeast region, northern

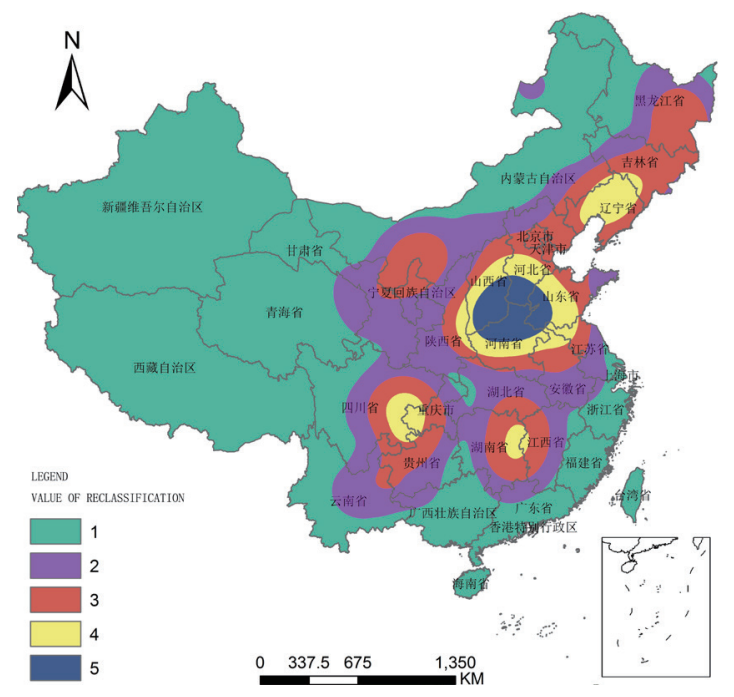

Fig. 3. (Color online) Spatial distribution of coalresource-exhausted cities after reclassification.

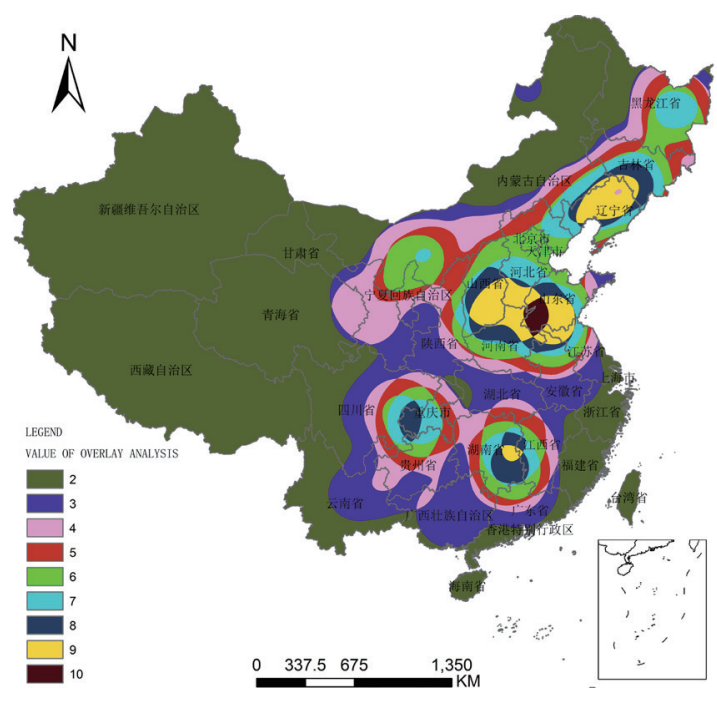

Fig. 4. (Color online) Distribution of areas suitable for development of coal mine industrial heritage tourism. 
Huang-Huai, the northeast of central China and northwest China, the east of northwest China, and central Jiangnan. The urban agglomerations involved mainly include the central and southern Liaoning urban agglomerations, the Harbin-Changchun urban agglomerations, the Shandong peninsula urban agglomerations, the Beijing-Tianjin-Hebei urban agglomerations, the central plains urban agglomerations, the urban agglomerations in the middle reaches of the Yangtze River, the Chengdu-Chongqing urban agglomerations, and the Hu-Bao-E-Yu urban agglomerations. The corresponding provinces and cities are shown in Table 1.

\section{Determination of Timing of Development of Coal Mine Tourism Resources}

\subsection{Overall development ideas and objectives}

The development of China's coal industrial heritage should take supply-side structural reform as the main line and adhere to the five development concepts of "innovation, coordination, green, open, and sharing" based on the integration of "safety, technology, environment, and economy" ideas of coal mining science, directed by The State's 13th Five-year Plan for the Development of the Coal Industry (2016), Implementation Opinions on Accelerating the Construction of Green Mines (2017), and the Action Plan for the Clean and Efficient Use of Coal (2015-2020), and based on Opinions of the State Council on Promoting the Reform and Development of Tourism Industry (GF [2014] No. 31) and the Outline of National Industrial Tourism Development (2016-2025). In accordance with the gradient development rules, we should develop the industrial heritage tourism of resource-exhausted coal mines, give priority to provinces and cities with the first gradient with high industrial heritage value and resource exhaustion, and then gradually promote the development of provinces and cities with the second and third gradients.

Table 1

Regions suitable for development of mine industrial heritage tourism.

\begin{tabular}{|c|c|c|}
\hline $\begin{array}{c}\text { Region (urban } \\
\text { agglomerations involved) }\end{array}$ & Cities in first gradient & Cities in second gradient \\
\hline $\begin{array}{l}\text { Northeast region } \\
\text { (Liaozhong-south; } \\
\text { Harbin-Changchun) }\end{array}$ & $\begin{array}{c}\text { Shenyang, Fushun, Benxi, Dandong, Yingkou, } \\
\text { Liaoyang, Panjin, Fuxin, Jinzhou, Chaoyang, } \\
\text { Huludao, Jilin, Siping, Liaoyuan, Tonghua, } \\
\text { Changchun }\end{array}$ & $\begin{array}{l}\text { Harbin, Mudanjiang, Jixi, Hegang, } \\
\text { Shuangyashan, Hegang, Qitaihe }\end{array}$ \\
\hline $\begin{array}{l}\text { Eastern region } \\
\text { (Shandong peninsula; } \\
\text { Beijing-Tianjin-Hebei) }\end{array}$ & $\begin{array}{c}\text { Jinan, Liaocheng, Tai’an, Jining, Zaozhuang, } \\
\text { Dezhou, Linyi, Zibo, Laiwu, Binzhou, Weifang, } \\
\text { Xuzhou, Lianyungang }\end{array}$ & $\begin{array}{l}\text { Qingdao, Yantai, Huai'an, Yancheng, } \\
\text { Beijing, Tianjin, Shaoguan, Qingyuan }\end{array}$ \\
\hline $\begin{array}{l}\text { Central region } \\
\text { (central plains; middle } \\
\text { reaches of Yangtze River) }\end{array}$ & $\begin{array}{l}\text { Shijiazhuang, Xingtai, Handan, Xingtai, } \\
\text { Hengshui, Baoding, Cangzhou, Jiaozuo, } \\
\text { Xinxiang, Anyang, Puyang, Kaifeng, Xuchang, } \\
\text { Heze, Shangqiu, Zhoukou, Huaibei, Huainan, } \\
\text { Luzhou, Bengbu, Taiyuan, Jinzhong, Changzhi, } \\
\text { Jincheng, Yuncheng, Linfen, Luliang, Xiangtan, } \\
\text { Zhuzhou, Luzhou, Pingxiang, Ganzhou, Ji'an }\end{array}$ & $\begin{array}{l}\text { Qinhuangdao, Tangshan, Chengde, } \\
\text { Zhumadian, Nanyang, Sanmenxia, } \\
\text { Luzhou, Lu'an, Hefei, Yueyang, } \\
\text { Changde, Loudi, Shaoyang, Yongzhou, } \\
\text { Yichun, Xinyu, East Ganzhou }\end{array}$ \\
\hline $\begin{array}{l}\text { Western region } \\
\text { (Chengdu-Chongqing; } \\
\text { Hu-Bao-E-Yu) }\end{array}$ & Chongqing & $\begin{array}{l}\text { Chengdu, Suining, Neijiang, Leshan, } \\
\text { Nanchong, Yibin, Guang'an, Dazhou, } \\
\text { Wuhai, Ordos, Alxa League, Yinchuan, } \\
\text { Yulin, Shizuishan, Wuzhong }\end{array}$ \\
\hline
\end{tabular}


Tourism resources assessment, environmental renewal, ecological restoration, landscape reconstruction, cultural reproduction, and other means are used to create mining heritage tourist attractions with regional characteristics. Functional areas of industrial heritage tourism or a cross-regional industrial heritage tourism belt is formed by connecting scenic spots associated with industrial heritage that have been formed or are under construction, relying on the complete mining heritage unit. In the future, a "One Belt and One Road" industrial heritage tourism corridor will be established.

The abandoned mining areas, which urgently require economic transformation and represent the progress of productivity and social development in a particular era, should be mainly developed. For example, many cities in northeast China have exhausted their coal resources and have serious economic and social problems. Therefore, industrial tourism is urgently needed to facilitate the economic transformation of cities.

Through the development of coal mine industrial heritage tourism, China should strive to solve the problem of the reuse of resource-exhausted coal mines, optimize the structure and layout of the coal industry, promote clean, efficient, and low-carbon development, and explore a new mechanism for the integrated development of the coal industry. Through the development of coal industrial heritage tourism, the supply of industrial tourism products will be enriched, promoting the optimization of urban functions and urban spaces, and ultimately realizing the economic transformation of mining cities, mineral resource recycling, an improved living environment and quality of life, and various other goals.

\subsection{Creating distinctive industrial heritage tourism destinations of coal mines}

The provinces and cities included in the first level identified above should be developed as a priority, such as Liaoning, Jilin, Shandong, Jiangsu, Hebei, Henan, Anhui, Shanxi, Jiangxi, Chongqing, and other provinces. According to their location conditions, resource endowments, economic conditions, and regional characteristics, these places should combine the historical value, technical value, social significance, and scientific research value of the old industrial and mining areas, and integrate tourism elements such as eating, toilet facilities, traveling, purchasing, and entertainment in order to develop new types of experience, interactivity, rich cultural connotations, and unique entertainment tourism products that are consistent with the original industrial culture.

\subsection{Forming transregional clusters of coal mine industrial heritage tourism}

In combination with the construction of more mature industrial heritage tourism destinations, cross-regional unions should be developed and multicenter clusters devoted to coal mine industrial heritage tourism should be built. By taking a railway as the main line and organically connecting multiple industrial heritage tourism destinations with similar or related cultural backgrounds, four coal industry heritage tourism agglomeration areas should be formed, which are the northeast region, core areas (northern Huang-Huai, the northeast region, and the northeast of central China and northwest China), the east of southwest China, and central Jiangnan. 
By taking the Haizhou Surface Mine National Mine Park, Hegang National Mine Park, and Jixi Hengshan National Mine Park as centers for development and using the Middle East rail as the main line and the Changji and Hali railways as branch lines, the coal mines in northeast China with high values of tourism resources and exhausted coal resources should be developed gradually to form an industrial heritage tourism cluster.

By taking the Kailuan National Mine Park, Huaibei National Mine Park, Zhongxing National Mine Park, Jinhuagong National Mine Park, Shijiaying National Mine Park, and Jiaozuo National Mine Park as centers for development and using the Jing-Guang, Jing-Jiu, and Long-Hai lines as the main lines, the coal mines with high values of tourism resources and exhausted coal resources should be developed gradually to form an industrial heritage tourism cluster in northern Huanghuai, central China, and the east of northwest China.

By taking the Jiayang National Mine Park and Zhongxing National Mine Park as centers for development and using the Cheng-Yu, Cheng-Da, and Chuan-Qian lines as the main lines, coal mines with high values of tourism resources and exhausted coal resources in various regions should be developed to form an industry heritage tourism cluster in the east of southwest China.

By taking the Anyuan National Mine Park as a center for development and using the JingGuang and Xiang-Gui lines as the main lines, the old mining areas with exhausted coal resources should be developed to form an industrial heritage cluster in central Jiangnan.

\section{Conclusions}

On the basis of the theory of industrial heritage value, this article comprehensively categorizes the importance of coal mines that operated during the history of modern coal mining from 1840 to 1970 and evaluates the value of tourism resources in each coal mine. By combining the values of coal mine tourism resources with the point data of coal-resource-exhausted cities, the nuclear density analysis method is used to form corresponding nuclear density distribution maps; nuclear density reclassification and assignment and overlay analysis are used to identify the key cities and regions for the development of coal mine industrial tourism. On this basis, the development sequence and measures for the development of coal mine industrial heritage tourism are proposed. The conclusions of the research are as follows.

Coal mine tourism resources can be identified by the organic integration of nuclear density analysis, the reclassification of the nuclear density distribution, and superposition analysis. This technique is also important for providing guidance and reference values for the identification of tourism resources with exhausted-coal-mine resources.

Coal mine tourism resources are mainly concentrated in the following regions: the northeast region, northern Huang-Huai, the northeast of central China and northwest China, the east of northwest China, and central Jiangnan. The urban agglomerations involved mainly include the central and southern Liaoning urban agglomerations, the Harbin-Changchun urban agglomerations, the Shandong peninsula urban agglomerations, the Beijing-Tianjin-Hebei urban agglomerations, the central plains urban agglomerations, the urban agglomerations in the middle reaches of the Yangtze River, the Chengdu-Chongqing urban agglomerations, and the Hu-Bao-E-Yu urban agglomerations. 
In the future, the development of coal mine industrial heritage tourism will be carried out in accordance with the gradient development law. Priority will be given to the provinces and cities of the first gradient, and then the provinces with the second and third gradients will be gradually developed. Industrial heritage tourism destinations that have been built or are under construction will be connected to form four coal mine industrial heritage tourism clusters: central-southern Liaoning, core areas (northern Huang-Huai, central China, and the east of northwest China), the east of southwest China, and central Jiangnan.

\section{Acknowledgments}

This study was carried out as part of a major consulting project of the Chinese Academy of Engineering (2020-XZ-13) and an institute-local cooperation project of the Chinese Academy of Engineering (2020SX5) .

\section{References}

1 W. White: Mining Heritage and Tourism: A Global Synthesis, M. V. Conlin and L. Jolliffe, Eds. (Routledge, London and New York, 2011) 1st ed., Chap. 2.

2 M. J. Balcar and D. G. Pearce: Tourism Manage. 17 (1996) 203. https://doi.org/10.1016/0261-5177(96)00007-6

3 D. Cole: J. Sustainable Tourism 12 (2004) 480. https://doi.org/10.1080/09669580408667250

4 Q. Wu, Y. F. Cui, and J. W. Liu: Hydrogeol. Eng. Geol. 34 (2007) 1. https://doi.org/10.3969/ j.issn.1000-3665.2007.04.030

5 J. H. Yu, J. M. Li, and W. Z. Zhang: J. Geogr. Sci. 73 (2018) 677. https://doi.org/10.11821/dlxb201804007

6 G. J. Hospers: Eur. Planning Stud. 10 (2002) 397. https://doi.org/10.1080/09654310220121112

7 D. Pella and S. Pellzza: Tunnelling Underground Space Technol. 10 (1995) 179. https://doi.org/10.1016/08867798(95)00006-k

8 D. Cole: J. Sustainable Tourism 12 (2004) 379. https://doi.org/10.1080/09669580408667250

9 M. A. Rudd and J. A. Davis: J. Sustainable Tourism 36 (1998) 85. https://doi.org/10.1177/004728759803600310

10 L. L. Li and S. Dietrich: Human Geogr. 18 (2003) 20. https://doi.org/10.3969/j.issn.1003-2398.2003.06.005

11 Y. Wu and Y. F. Shen: Tourism Sci. 21 (2007) 22. https://doi.org/10.3969/j.issn.1006-575X.2007.01.005

12 J. Zhang and T. S. Li: J. Northwestern University (Natural Science Edition) 37 (2007) 493. https://doi.org/ doi:10.16152/j.cnki.xdxbzr.2007.03.034

13 X. G. Gu and D. G. Wang: Econ. Manag. 19 (2006) 69. https://doi.org/10.19616/j.cnki.bmj.2006.19.017

14 L. L. Li and D. Soyez: J. Heritage Tourism 12 (2017) 296. https://doi.org/10.1080/1743873x.2016.1236799

15 X. Y. Dai and W. M. Que: Sci. Geogr. Sinica 32 (2012) 31. https://doi.org/10.13249/j.cnki.sgs.2012.01.006

16 X. Y. Dai, C. C. Tang, J. M. Liu, and A. Q. Zhu: Tourism Tribune 29 (2014) 52. https://doi.org/10.3969/ j.issn.1002-5006.2014.11.16

17 X. Q. He and X. W. Wang: Sci. Technol. Manag. Land Resour. 31 (2014) 50. https://doi.org/10.3969/ j.issn.1009-4210.2014.05.008

18 P. F. Xie: Tourism Manag. 27 (2006) 1321. https://doi.org/10.1016/j.tourman.2005.06.010.

19 Y. Xue: J. Hubei Polytechnic University (Humanities and Social Science) 5 (2013) 335. https://doi.org/10.3969/ j.ISSN.2095-4662.2013.05.002

20 Y. Xue: J. Henan Polytechnic University (Social Sciences) 16 (2015) 335. https://doi.org/10.3969/ j.issn.1673-9779.2015.03.014 


\section{About the Authors}

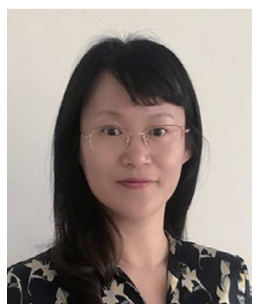

Qiu-Ju Wang received her B.S. degree from Harbin Architecture University, China, in 1994 and her Ph.D. degree from Northeast Agricultural University, China, in 2007. Since 2016, she has been a professor at Beijing Union University. Her research interests are in industrial tourism and tourism management. (lytwangqiuju@buu.edu.cn)

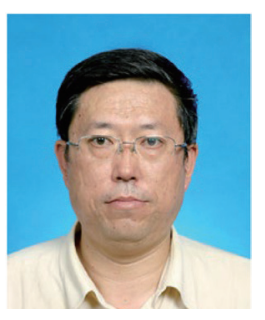

Zhi-Hong Wang graduated from Shenyang University, China, in 1988. He is an engineer in the School of Civil Engineering at Shenyang University. His research interests are in the HVAC system and equipment.

(wzh413366@163.com)

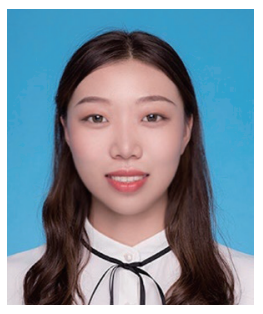

Jia-Li Zhou received her B.S. degree from Luoyang Normal University, China, in 2019, and she is currently pursuing further studies at Beijing Union University. Her research interests are in industrial tourism and tourism management. (Zj1ly1225@126.com)

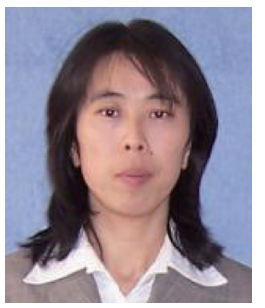

Shuang Dong received her B.S. degree from Shenyang Institute of Technology, China, in 1992 and her M.S. and Ph.D. degrees from Beijing University of Posts and Telecommunications, China, in 2002 and 2007, respectively. She is an associate professor in the Management College at Beijing Union University. Her research interests include data mining and information technology. (gltdongshuang@buu.edu.cn) 